\title{
What is The Correct Mechanical Model of Aorta Artery
}

\author{
Kadir Mercan, Ömer Civalek ${ }^{*}$ \\ Akdeniz University, Civil Engineering Department, \\ Division of Mechanics, Antalya-TURKIYE \\ ${ }^{*}$ E-mail address: civalek@yahoo.com
}

Received date: June 2017

Accepted Date: July 2017

\begin{abstract}
:
Aorta artery is the most vital artery in humans and almost all animals. Aorta artery is also the largest artery in human body. This artery is the first artery coming out from the left ventricle of the heart and extending down to the abdomen, where it splits into two smaller iliac arteries. Aorta artery conveys oxygenated blood to all parts of the body so that this artery is the one, which is under the influence of the highest blood pressure. It is well known that aorta artery consists of three main layers, which cover five sub-layers. In this paper, we aimed to show the difference between functionally graded material (FGM) and laminated composite material and to show which model fits to the structure of aorta artery.
\end{abstract}

Keywords: Aorta artery, composite materials, functionally graded materials, laminated composite materials.

\section{Introduction}

The mechanic model of aorta artery has a long history and variety in literature. For example, a fundamental paper about mechanic model of aorta artery presented by Gozna et al. in 1974 with the effect of age in man [1]. Gozna et al. have found regression equations between aging and aorta artery mechanic behavior. These equations have showed that there is a linear relation between aging and aorta artery mechanic behavior. More recently, the stability of aorta artery has been investigated in case of buckling under blood pressure by Han in 2007 [2]. Further researches of Han et al. proved that arteries may buckle and become turtous due to reduced axial strain, hypertensive pressure, and weakened artery wall [3-9]. In 2013, Han et al. has introduced new phenotypes, models, and applications of aorta artery [10]. In the review, Han et al. summarized the common forms of buckling that occurs in blood vessels including cross-sectional collapse, longitudinal twist buckling, and bent buckling. Also the phenomena, model analyses, experimental measurements, effect on blood flow, and clinical relevance have been discussed. From this and further works Han et al. clearly showed that mechanical buckling of aorta artery is an important issue for vasculature, in addition to wall stiffness and strength, and requires further studies [11-20]. 


\section{Anatomy of Aorta Artery}

It is well known that aorta artery is composed of three main layers like most of other arteries [21]. These layers are "intima", "media", and "adventitia" respectively from inner layer to outermost layer. Intima is the innermost layer of the artery which is covering the lumen side of vessels and it is composed of endothelial cells and lines the entire circulatory system, from the heart and the large arteries all the way down to the very tiny capillary beds. The intima layer also contains extracellular matrix and a supporting layer of collagenous tissue. Endothelial cells sorted in a single layer along the lumen side. Media is the muscular middle layer of the arteries and veins. It is composed of smooth muscle layers. Adventitia is outermost layer of vessels surrounding the media layer. It is mainly composed of collagen and, in arteries, is supported by external elastic lamina . The demonstration of these three main layers have been shown in Fig. 1.

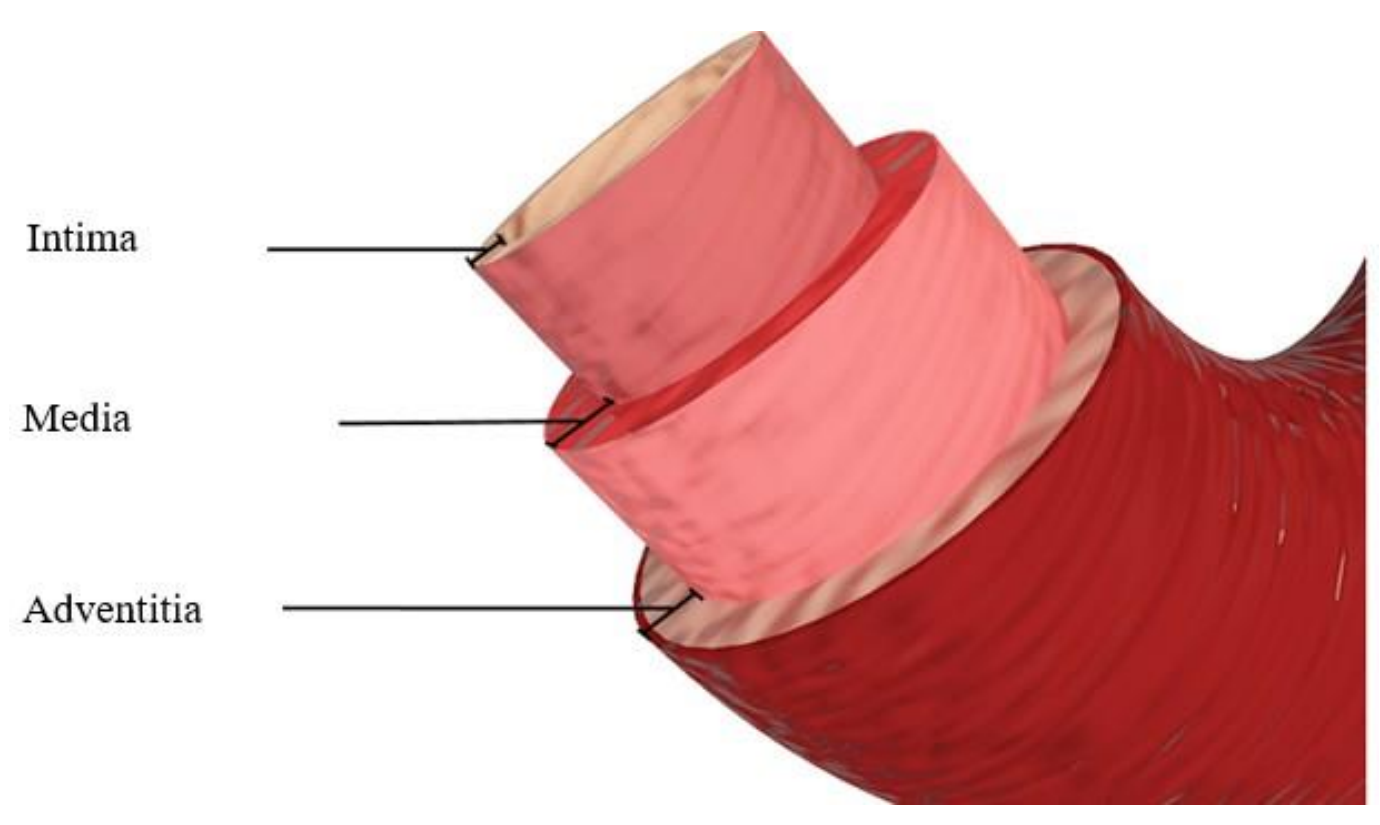

Fig. 1. Main layers of aorta artery

More specifically, these three main layers "intima", "media", and "adventitia" consist of five sublayers. These sub-layers are Endotel, internal elastic layer, smooth muscle, external elastic layer, collagens and elastic tendons from inside to outside of aorta artery respectively as it is shown in Fig. 2. 


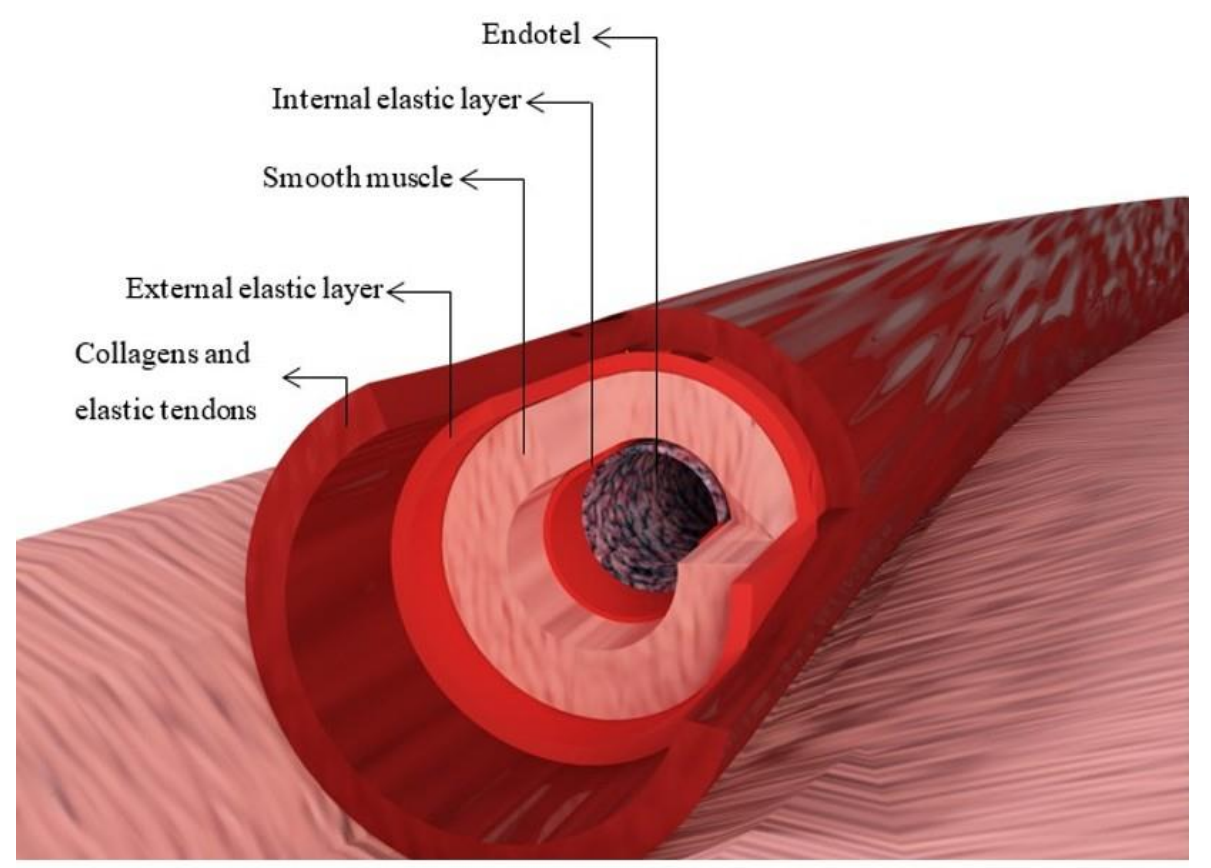

Fig. 2. Sub-layers of aorta artery

In 2005, Holzapfel et al. have made an experimental research to determine the material properties of the layers of aorta artery separately [22]. Within these experiments, 13 nonstenotic human aorta artery have been harvested at autopsies. The age of human were mean $71.5 \pm 7.3$ years old. The artery samples have been subjected to cyclic quasi-static uniaxial tension tests from the individual layers in axial and circumferential directions. The outer diameter to total wall thickness ratio was $0.189 \pm 0.014$ and the ratios of intima, media, and adventitia to total thickness were $0.27 \pm 0.02,0.36 \pm 0.03,0.4 \pm 0.03$ respectively. The axial stretch was $1.044 \pm 0.06$ and decreased with age of humans. Holzapfel et al. have found that the stress-stretch responses for the individual tissues performed pronounced mechanical heterogeneity. According to researches and experiments, intima have been found to be the stiffest layer and media the softest. Although intima and media have been found the stiffest and softest layers, these two layers have performed similar ultimate tensile stresses. These values have been found three times smaller than ultimate tensile stresses which have been calculated for adventitia ( $1430 \pm 604 \mathrm{kPa}$ circumferential and $1300 \pm 692 \mathrm{kPa}$ longitudinal). This study have clearly showed that aorta artery need to be modelled as composite structure which consist of three solid mechanically relevant layers with different material properties. The innermost layer "intima" have performed significant thickness, load-bearing capacity, and mechanical strength compared with other main layers "adventitia and media". In order to calculate the material properties of the layers of aorta artery, Holzapfel et al. harvested thirteen hearts from ten men and three women within 24 hour of their death. A scalpel has been used in order to separate three main layers. After separating layers, uniaxial tensile tests with bidimensional measurements were performed with the aid computer controlled, screw-driven high-precision tensile testing machine. According to Holzapfel et al., the mean density of adventitia, media, and intima have been calculated dimensionless as $0.55 \pm 0.18,0.25 \pm 0.09$, $0.51 \pm 0.14$ and the average stiffness have been calculated as $7.56 \pm 4.66 \mathrm{kPa}, 1.27 \pm 0.63 \mathrm{kPa}$, $27.90 \pm 10.59 \mathrm{kPa}$ respectively [22]. 

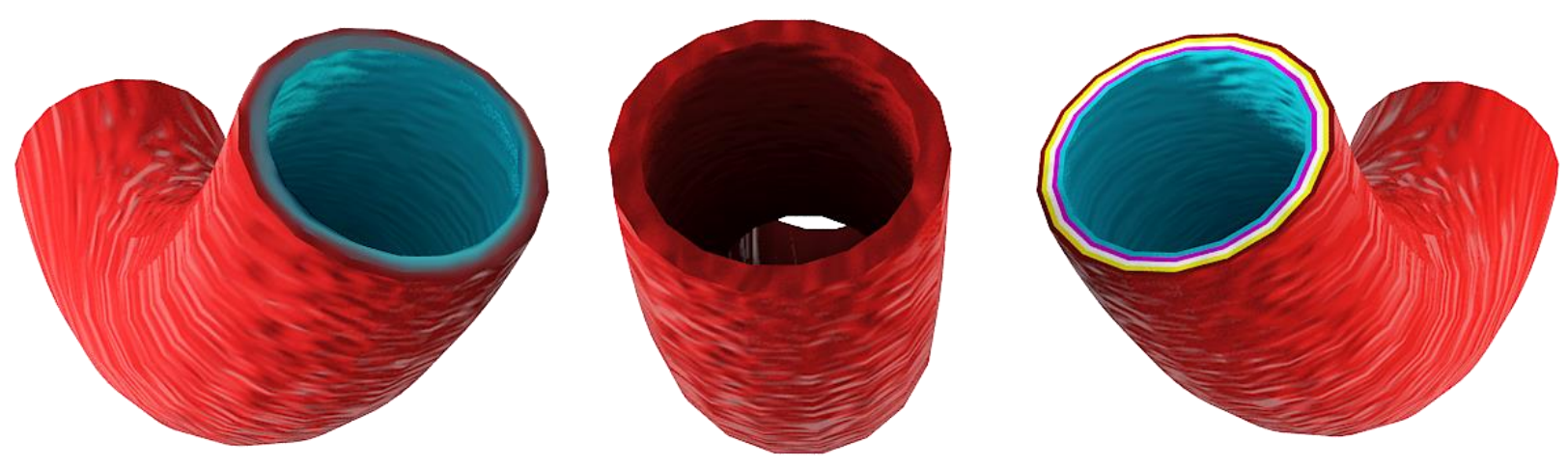

Fig. 3. FGM, single layered, and laminated models of aorta artery

In Fig. 3, different mechanical models of aorta artery have been demonstrated. Functionally graded material (FGM) and laminated composite materials have been chosen to be applied to aorta artery. As it can be seen in the middle, also single layered model have been demonstrated. In vivo, aorta artery is embedded in tissue and this tissue can be modeled as elastic matrix. In literature many paper can be found about static and dynamic analysis of beams and shells with composite materials [2325].

\section{Functionally Graded Materials (FGM)}

Functionally graded materials (FGM) are relatively new advanced composite materials compared other composite materials. After the invasion of this composite materials, great deals of research have been made on the production and applications process of this new material concept. Functionally graded materials are characterized by gradually changed physical properties.

$$
p=p_{0}\left[1+\frac{p_{-1}}{T}+p_{1} T+p_{2} T^{2}+p_{3} T^{3}\right]
$$

In Eq. (1) $p_{i}$ are the coefficients of temperature defined in the unit of Kelvin and them are unique to the constituent materials.

$$
p=\sum_{j=1}^{k} p_{j} V_{f}
$$

In Eq. (2) $p_{j}$ and $V_{f}$ are the material property and volume fraction of the constituent material $j$, respectively. The sum of volume fraction can be stated as

$$
\sum_{j=1}^{k} V_{f}=1
$$

To adopt the aorta artery as functionally graded material, a shell model with uniform thickness can be used. The volume fraction of the shell can be stated as 


$$
\mathrm{V}_{\mathrm{f}}=\left(\frac{\mathrm{z}}{\mathrm{h}}+\frac{1}{2}\right)^{\mathrm{N}}
$$

The power-law exponent is defined by $\mathrm{N}$. The material properties for a two-constituent functionally graded can be stated as [26]

$$
\begin{aligned}
& E(z)=\left(E_{1}-E_{2}\right)\left(\frac{z}{h}+\frac{1}{2}\right)^{N}+E_{2} \\
& v(z)=\left(v_{1}-v_{2}\right)\left(\frac{z}{h}+\frac{1}{2}\right)^{N}+v_{2} \\
& \rho(z)=\left(\rho_{1}-\rho_{2}\right)\left(\frac{z}{h}+\frac{1}{2}\right)^{N}+\rho_{2}
\end{aligned}
$$

\section{Laminated Composite Materials}

Laminated composite materials have attracted much attention due to their higher resistance, lighter weight when compared with traditional materials. Laminated composite materials have been widely used in aerospace industry, automotive industry and material engineering. Many researches have been published papers aimed to investigate the applications of laminated composite materials to shells, plates, and beams in case of static and dynamic analyses [27-35].

General equations of laminated composite materials can be stated as follows

$$
\begin{aligned}
\sigma_{\mathrm{i} 1} & =\frac{\mathrm{E}_{\mathrm{i} 1}}{1-\mathrm{v}_{\mathrm{i} 12} \mathrm{v}_{\mathrm{i} 21}}\left(\varepsilon_{\mathrm{i} 1}+\mathrm{v}_{\mathrm{i} 21} \varepsilon_{\mathrm{i} 12}\right) \\
\sigma_{\mathrm{i} 2} & =\frac{\mathrm{E}_{\mathrm{i} 2}}{1-\mathrm{v}_{\mathrm{i} 12} \mathrm{v}_{\mathrm{i} 21}}\left(\mathrm{v}_{\mathrm{i} 12} \varepsilon_{\mathrm{i} 1}+\varepsilon_{\mathrm{i} 2}\right) \\
\tau_{\mathrm{i} 12} & =\mathrm{G}_{\mathrm{i} 12} \gamma_{\mathrm{i} 12}=2 \mathrm{G}_{\mathrm{i} 12} \varepsilon_{\mathrm{i} 12}
\end{aligned}
$$

Where $\mathrm{E}_{\mathrm{i} 1}$ and $\mathrm{E}_{\mathrm{i} 2}$ are the Young's modulus in longitudinal "1" and transverse " 2 " direction respectively. On the other hand, $\mathrm{v}_{\mathrm{i} 12}$ is the Poisson's ratio for which strains are in longitudinal direction " 1 " and stress in transverse direction " 2 ". Similarly, $\mathrm{G}_{\mathrm{i} 12}$ is the shear modulus.

Eqs. (8-10) can be written in matrix form as follows

$$
\left\{\begin{array}{c}
\sigma_{1} \\
\sigma_{2} \\
\tau_{12}
\end{array}\right\}=\left[\begin{array}{ccc}
\mathrm{Q}_{11} & \mathrm{Q}_{12} & 0 \\
\mathrm{Q}_{21} & \mathrm{Q}_{22} & 0 \\
0 & 0 & \mathrm{Q}_{66}
\end{array}\right]\left\{\begin{array}{c}
\varepsilon_{1} \\
\varepsilon_{2} \\
\gamma_{12}
\end{array}\right\}
$$

By simplifying Eq. (11) we obtain 


$$
\{\sigma\}=[Q]\{\varepsilon\}
$$

Where

$$
\begin{aligned}
\mathrm{Q}_{11} & =\frac{\mathrm{E}_{1}}{1-\mathrm{v}_{12} \mathrm{v}_{21}} \\
\mathrm{Q}_{12}=\mathrm{Q}_{21} & =\mathrm{v}_{21} \frac{\mathrm{E}_{1}}{1-\mathrm{v}_{12} \mathrm{v}_{21}}=\mathrm{v}_{12} \frac{\mathrm{E}_{1}}{1-\mathrm{v}_{12} \mathrm{v}_{21}} \\
\mathrm{Q}_{22} & =\frac{\mathrm{E}_{2}}{1-\mathrm{v}_{12} \mathrm{v}_{21}} \\
\mathrm{Q}_{66} & =\mathrm{G}_{12}
\end{aligned}
$$

According to Betty-Maxwell theorem the Young's modulus and Poisson's ratios should fulfil the following equation

$$
\mathrm{E}_{1} \mathrm{v}_{21}=\mathrm{E}_{2} \mathrm{v}_{12}
$$

\section{Concluding remarks}

In present paper the most convenient mechanical model of aorta artery have been investigated. Two of most used composite materials types have been analyzed. Functionally graded materials and laminated composite materials models fundamental equations have been given. As it can be seen from Fig. 2, aorta artery has a layered structure which is composed of three main layers which consist of five sub-layers. Each layer has their own material properties (density, Young's modulus etc.). To conclude it is possible to say that aorta artery can be modelled by using laminated composite material theories. Three main layers can be adapted in laminated composite theories or to have more accurate result, five sub-layers can be adapted in laminated composite theories in order to investigate the mechanical behavior of aorta artery.

\section{Acknowledgements}

The financial support of the Scientific Research Projects Unit of Akdeniz University is gratefully acknowledged.

\section{References}

[1] Gozna, E.R., Marble, A.E., Shaw, A., Holland, J.G., Age-Related Changes in Mechanics of Aorta and Pulmonary-Artery of Man. Journal of Applied Physiology, 36(4), 407-411, 1974.

[2] Han, H.C., A biomechanical model of artery buckling. Journal of Biomechanics, 40(16), 3672-3678, 2007. 
[3] Han, H.C., The Theoretical Foundation for Artery Buckling Under Internal Pressure. Journal of Biomechanical Engineering-Transactions of the Asme, 131(12), 2009.

[4] Lee, Y.U., Hayman, D., Sprague, E.A., Han, H.C., Effects of Axial Stretch on Cell Proliferation and Intimal Thickness in Arteries in Organ Culture. Cellular and Molecular Bioengineering, 3(3), 286-295, 2010.

[5] Lee, Y.U., Luo, J., Sprague, E., Han, H.C., Comparison of Artery Organ Culture and Coculture Models for Studying Endothelial Cell Migration and Its Effect on Smooth Muscle Cell Proliferation and Migration. Annals of Biomedical Engineering, 38(3), 801-812, 2010.

[6] Datir, P., Lee, A.Y., Lamm, S.D., Han, H.C., Effects of Geometric Variations on the Buckling of Arteries. International Journal of Applied Mechanics, 3(2), 385-406, 2011.

[7] Hayman, D.M., Xiao, Y.M., Yao, Q.P., Jiang, Z.L., Lindsey, M.L., Han, H.C., Alterations in Pulse Pressure Affect Artery Function. Cellular and Molecular Bioengineering, 5(4), 474-487, 2012.

[8] Liu, Q., Han, H.C., Mechanical buckling of artery under pulsatile pressure. Journal of Biomechanics, 45(7), 1192-1198, 2012.

[9] Garcia, J.R., Lamm, S.D., Han, H.C., Twist buckling behavior of arteries. Biomechanics and Modeling in Mechanobiology, 12(5), 915-927, 2013.

[10] Han, H.C., Chesnutt, J.K.W., Garcia, J.R., Liu, Q., Wen, Q., Artery Buckling: New Phenotypes, Models, and Applications. Annals of Biomedical Engineering, 41(7), 13991410, 2013.

[11] Lee, A.Y., Sanyal, A., Xiao, Y.M., Shadfan, R., Han, H.C., Mechanical instability of normal and aneurysmal arteries. Journal of Biomechanics, 47(16), 3868-3875, 2014.

[12] Liu, Q., Wen, Q., Mottahedi, M., Han, H.C., Artery buckling analysis using a four-fiber wall model. Journal of Biomechanics, 47(11), 2790-2796, 2014.

[13] Xiao, Y.M., Hayman, D., Khalafvand, S.S., Lindsey, M.L., Han, H.C., Artery buckling stimulates cell proliferation and NF-kappa B signaling. American Journal of PhysiologyHeart and Circulatory Physiology, 307(4), H542-H551, 2014.

[14] Zhang, J.Z., Liu, Q., Han, H.C., An In Vivo Rat Model of Artery Buckling for Studying Wall Remodeling. Annals of Biomedical Engineering, 42(8), 1658-1667, 2014.

[15] Khalafvand, S.S., Han, H.C., Stability of Carotid Artery Under Steady-State and Pulsatile Blood Flow: A Fluid-Structure Interaction Study. Journal of Biomechanical EngineeringTransactions of the Asme, 137(6), 2015.

[16] Luetkemeyer, C.M., James, R.H., Deuarakonda, S.T., Le, V.P., Liu, Q., Han, H.C., Wagenseil, J.E., Critical buckling pressure in mouse carotid arteries with altered elastic fibers. Journal of the Mechanical Behavior of Biomedical Materials, 46, 69-82, 2015.

[17] Qi, N., Gao, H., Ogden, R.W., Hill, N.A., Holzapfel, G.A., Han, H.C., Luo, X.Y., Investigation of the optimal collagen fibre orientation in human iliac arteries. Journal of the Mechanical Behavior of Biomedical Materials, 52, 108-119, 2015. 
[18] Sanyal, A., Han, H.C., Artery buckling affects the mechanical stress in atherosclerotic plaques. Biomedical Engineering Online, 14, 2015.

[19] Fatemifar, F., Han, H.C., Effect of Axial Stretch on Lumen Collapse of Arteries. Journal of Biomechanical Engineering-Transactions of the Asme, 138(12), 2016.

[20] Mottahedi, M., Han, H.C., Artery buckling analysis using a two-layered wall model with collagen dispersion. Journal of the Mechanical Behavior of Biomedical Materials, 60, 515 $524,2016$.

[21] Mercan, K., Civalek, Ö., A Simple Buckling Analysis of Aorta Artery. International Journal of Engineering \& Applied Sciences (IJEAS), 7(4), 34-44, 2016.

[22] Holzapfel, G.A., Sommer, G., Gasser, C.T., Regitnig, P., Determination of layer-specific mechanical properties of human coronary arteries with nonatherosclerotic intimal thickening and related constitutive modeling. American Journal of Physiology-Heart and Circulatory Physiology, 289(5), H2048-H2058, 2005.

[23] Mercan, K., Ersoy, H., Civalek, O., Free vibration of annular plates by discrete singular convolution and differential quadrature methods. Journal of Applied and Computational Mechanics, 2(3), 128-133, 2016.

[24] Demir, Ç., Akgöz, B., Erdinç, M.C., Mercan, K., Civalek, Ö., Elastik Bir Malzeme İle Temas Halinde Olan Grafen Tabakanin Titreşim Hesabi. Gazi Üniversitesi MühendislikMimarlık Fakültesi Dergisi, 32(2), 2017.

[25] Mercan, K., Civalek, Ö., Buckling analysis of Silicon carbide nanotubes (SiCNTs) with surface effect and nonlocal elasticity using the method of HDQ. Composites Part B: Engineering, 114, 34-45, 2017.

[26] Loy, C.T., Lam, K.Y., Reddy, J.N., Vibration of functionally graded cylindrical shells. International Journal of Mechanical Sciences, 41(3), 309-324, 1999.

[27] Civalek, Ö., Demir, Ç., Akgöz, B., Static analysis of single walled carbon nanotubes (SWCNT) based on Eringen's nonlocal elasticity theory. International Journal of Engineering and Applied Sciences, 2(1), 47-56, 2009.

[28] Civalek, Ö., Korkmaz, A., Demir, Ç., Discrete singular convolution approach for buckling analysis of rectangular Kirchhoff plates subjected to compressive loads on two-opposite edges. Advances in Engineering Software, 41(4), 557-560, 2010.

[29] Gürses, M., Akgöz, B., Civalek, Ö., Mathematical modeling of vibration problem of nanosized annular sector plates using the nonlocal continuum theory via eight-node discrete singular convolution transformation. Applied Mathematics and Computation, 219(6), 3226-3240, 2012.

[30] Akgöz, B., Civalek, Ö., A novel microstructure-dependent shear deformable beam model. International Journal of Mechanical Sciences, 99, 10-20, 2015.

[31] Demir, Ç., Civalek, Ö., Nonlocal Deflection Of Microtubules Under Point Load. International Journal of Engineering and Applied Sciences, 7(3), 33-39, 2015. 
[32] Emsen, E., Mercan, K., Akgöz, B., Civalek, Ö., Modal analysis of tapered beam-column embedded in Winkler elastic foundation. International Journal of Engineering \& Applied Sciences, 7(1), 25-35, 2015.

[33] Mercan, K., Demir, C., Akgöz, B., Civalek, Ö., Coordinate Transformation for Sector and Annular Sector Shaped Graphene Sheets on Silicone Matrix. International Journal of Engineering \& Applied Sciences (IJEAS), 7(2), 56-73, 2015.

[34] Demir, Ç., Civalek, Ö., Nonlocal Finite Element Formulation for Vibration. International Journal of Engineering \& Applied Sciences (IJEAS), 8(2), 109-117, 2016.

[35] Mercan, K., Civalek, Ö., Buckling Analysis of Silicon Carbide Nanotubes (SiCNTs). International Journal of Engineering \& Applied Sciences (IJEAS), 8(2), 101-108, 2016. 